\title{
On Optimal Skill Distribution in a Mirrleesian Economy*
}

\author{
Hakkı Yazıcı** \\ Sabancl University
}

\author{
Tin Cheuk Leung*** \\ Wake Forest University
}

\begin{abstract}
This paper analyzes optimal distribution of skills in an economy where, in addition to choosing income taxes, a redistributive government also chooses the dispersion of skill distribution given the average skill level of the economy. We find that perfectly unequal skill distribution in which one group has a very high skill level and the rest are completely unskilled is socially optimal.
\end{abstract}

Keywords: skill distribution, optimal taxation, redistribution, efficiency

JEL Classification: $\mathrm{H} 2$.

\section{Yeniden Dağıtımcı Optimal Vasıf Dağılımı}

\section{Özet}

$\mathrm{Bu}$ makale yeniden dağıtımı amaçlayan ve doğrusal bir vasıf kısıtına maruz kalan bir sosyal planlamacının optimal vasıf dağıtımını nasıl yapması gerektiğini incelemektedir. Sonçlarımız bütün vasıfların bir grupta toplandığı tümden eşitsiz vasıf dağılımın optimal olduğunu göstermektedir.

Anahtar Kelimeler: vasıf dağılımı, optimal vergilendirme, yeniden dağıtım, verimlilik

Jel Sinıflamasi: $\mathrm{H} 2$

$\mathrm{P}$ eople are heterogenous in the skills with which they turn effort into output. A central question in normative public economics is how to efficiently redistribute resources from those with high skills to those with low skills. One policy tool that achieves such redistribution is income taxation. As it is well-known since the seminal work of Mirrlees (1971), however, income taxation is distortionary when individuals' skills and efforts are private information.

* We would like to thank James Mirrlees for his detailed comments and encouragement. We also thank Abdurrahman Aydemir, Larry Jones, Cüneyt Orman, Nicola Pavoni, Chris Phelan, and seminar participants at Ankara University SBF, ODTU, PET 10, TOBB-ETU, and the University of Barcelona.

** Hakk1 Yazıc1 is an Assistant Professor in the Faculty of Arts as Sciences at Sabanc1 University, Orhanlı, Tuzla, 34956, Istanbul, Turkey. E-mail: hakkiyazici@sabanciuniv.edu

*** Tin Cheuk Leung is an Assitant Professor in the Department of Economics at Walke Forest University, Box 7505, WinstonSalem NC27109, USA. E-mail: leungtc@wfu.edu 
In this paper, we consider an additional policy tool of redistribution. We do so by allowing a social planner to choose the dispersion of skill distribution of the economy, taking the average skill level as given. ${ }^{[1]}$ By choosing a less dispersed distribution, the planner can create an economy with more equal earnings capacity among agents. This implies a more equal distribution of consumption for given income taxes. It is important, though, to realize that changing skill distribution not only affects how total output is shared across agents, but also affects the overall productivity of the economy. The amount of output that can be produced by a given labor force depends on the skill distribution chosen. Taking this effect on productivity into account, we ask how the planner should use these two policy tools jointly for the efficient redistribution of resources.

To answer this question we consider a static Mirrleesian economy in which the planner chooses the skill distribution and income taxes. In the model, the planner first chooses the skill distribution, agents then draw their types from the skill distribution privately, the planner chooses the income tax system, and finally, agents work, pay taxes and consume. The main difference between our model and standard models in the optimal tax literature is the initial stage of skill distribution choice in which the planner, taking the average level of skills as given, chooses the dispersion of the skill distribution. We restrict the set of skill distributions available to the planner to discrete distributions with a finite number of mass points. The planner thus essentially chooses the value of the mass points. ${ }^{[2]}$

In such a world, at one extreme, the planner can choose a skill distribution in which the value of all mass points is equal to the average skill level. In this extreme, after the skill draw, all agents have the same earnings capacity. We call this the perfectly equal skill distribution. In this case, redistribution is carried out solely via skill distribution choice; there is no need for income taxation. At another extreme lies a skill distribution in which the value of all but one mass point is set to zero. In this extreme, after the draw, a fraction of agents have very high earnings capacity while the rest are completely unproductive. We call this the perfectly unequal skill distribution. Here, income taxes are heavily needed for redistribution. In between, there is a continuum of skill distributions available to the planner, each with a different level of skill inequality. The main result of our paper is striking: the perfectly unequal skill distribution is always socially optimal. In other words, it is optimal to use income taxation alone for redistribution.

In this paper, we assume that the planner faces a linear skill constraint with two mass points. More precisely, the planner chooses mass points $w 1, w 2$ subject to the following skill constraint,

$$
p_{1} w_{1}+p_{2} w_{2} \leq \alpha,
$$

[1] We do not take a stance on any particular interpretation of skill distribution choice. However, one may interpret this as a choice of education policy given that people attain a significant portion of their skills through learning.

[2] We make two assumptions here. First, the number of mass points is fixed. Second, the planner takes the probability attached to each mass point as given when he chooses the value of the mass points. The latter assumption is not important because our main result holds regardless of the probability assigned to each mass point. 
where $p_{1}, p_{2}$ are exogenous probabilities attached to the mass points and $\alpha$ is the average skill level in society. The assumption of linearity implies constant returns to individual skill attainment, and this feature of the model is important for our result. ${ }^{[3]}$ Under this assumption of linearity, we show that the socially optimal skill distribution is always perfectly unequal, i.e., $w_{i}=0$, for some $i$. The intuition for this result is as follows. Suppose that $w_{i}>0$, for all $i$. In this case, it is obvious that the optimal labor levels are positive for both types. Then, by moving to a skill distribution in which the type with a higher labor level has all the skills and setting the labor level of the other type to zero, the planner increases total output and decreases total disutility. This shows that increasing skill inequality benefits society because it increases productive efficiency. Under full information, income taxes are not distortionary, which means that the planner can distribute consumption according to its will, using income taxes at no cost. This implies the efficiency gain is the only effect of increasing skill inequality on the economy. Thus, under full information, perfectly unequal skill distribution is socially optimal. However, when skill levels are private information, income taxes are distortionary. Increasing skill inequality exacerbates the distortion associated with income taxation, because the benefit of pretending to be low-skilled is higher for the high-skilled agents when skill inequality is higher. Therefore, increasing skill inequality imposes a cost on society as well. We show, however, that the socially optimal skill distribution is still perfectly unequal.

The paper closest to ours is Cremer, Pestieau, and Racionero (2010). Their model setup is very similar to ours but also more general in the sense that they allow for a utility function that is non-separable between consumption and labor. Considering a general concave welfare function, the authors show that perfectly equal skill distribution (or, in their terminology, "complete wage equalization") is dominated in terms of social welfare by the perfectly unequal distribution under a linear skill constraint. In the current paper, we make a restrictive assumption by assuming that utility is separable between consumption and labor. However, at the same time, we go beyond comparing the two extreme skill distributions, and prove that the perfectly unequal skill distribution is the best in terms of social welfare among all feasible skill distributions under linear skill constraint, meaning that it is the socially optimal distribution.

A few other papers analyze comparative static properties of optimal allocations with respect to certain parameters of the skill distribution. Instead of providing a comprehensive survey of this literature, we will provide two brief examples. ${ }^{[4]}$ Brett and Weymark (2008) investigates the effect of changing an agent's skill level on the solution of a Mirrlees optimal income tax problem. Hamilton and Pestieau (2005) studies the effect on individual utilities of changing the fraction of individuals when the social welfare

\footnotetext{
[3] Allowing for non-linear skill constraints is an important extension, but it also complicates the analysis of optimal skill distributions significantly. Such an analysis is beyond the scope of this paper. In an accompanying paper Leung and Yazici (2017), we analyze precisely this issue.

${ }^{[4]}$ Other papers that provide such comparative static results are Boadway and Pestieau (2006), and Simula (2007).
} 
function is either maximin or maximax. The main difference between these papers and ours should be apparent: while we analyze the optimal skill distribution, they study only comparative static properties.

In our analysis we do not take a stance on any particular interpretation of the skill distribution choice. However, if we think that skills can be partly attained through education, our model may have implications for education policy. In this regard, the paper is related to several papers that consider education policy as a redistribution tool in the presence of income taxation.

Hare and Ulph (1979) shows that when agents' learning abilities are heterogenous and skill types are observable, the "optimal choice of education policy reinforces [the] redistributive effect of income tax." Bovenberg and Jacobs (2006) constructs a model in which agents choose the education level. The government can only influence education, and thus skill distribution, through education subsidies. They show that providing more subsidies to smarter agents (a regressive education policy) would make it more incentive compatible to undertake more redistribution through income taxes.

Another potential interpretation of skill distribution choice is related to Skill-Biased Technical Change (SBTC), which refers to "a shift in the production technology that favors skilled over unskilled labor by increasing its relative productivity" (Violante (2009)). Under this interpretation, the planner chooses the level of SBTC that determines the level of skill inequality between skilled and unskilled labor. For instance, suppose that the government is choosing the degree of computerization of the production process. In this case, a higher degree of computerization increases the productivity of some workers (those who are more prone to using computers) but decreases the productivity of the rest, thereby changing the skill distribution towards higher inequality. While most papers in the SBTC literature are positive studies of the growth and income distribution implications of SBTC, this paper could be interpreted as a normative analysis of the optimal level of SBTC. However, this interpretation of our model should be approached with caution because we treat skilled and unskilled labor as perfect substitutes as in almost all the Mirleesian taxation literature (see Naito (1999) and Stiglitz (1982) for exceptions), contrary to the empirically relevant case of production functions with complementarity.

The rest of this paper is structured as follows. In next section, we introduce the model formally. In the section after that, we analyze the optimal skill distribution problem and show our main results. Finally, last section concludes the paper.

\section{Model}

There is a unit measure of agents. They produce output individually according to the production function

$$
y=w l,
$$

where $y$ denotes output, $w$ denotes skill level, and $l$ denotes labor effort. Each agent's preference is given by

$$
u(c)-v(l),
$$


where $c$ is consumption and $u$ and $v$ satisfy $\mathrm{u}^{\prime},-u^{\prime \prime}, v^{\prime}>0$ and $v^{\prime \prime}>0$.

The novelty of our analysis is that we allow the planner to choose the distribution of skills. For tractability, we assume that the planner has to choose a distribution in which skills can take only two values, $w_{1}$ and $w_{2}$. The probability of drawing $w_{1}$ is $p_{1}$ and the probability of drawing $w_{2}$ is $p_{2}$. We allow the planner to choose $w_{1}$ and $w_{2}$, but $p_{1}$ and $p_{2}$ are exogenously given. We take the average skill level of the economy as given, at $\alpha$. We assume that the planner chooses $w_{1}$ and $w_{2}$ subject to a linear skill constraint:

$$
p_{1} w_{1}+p_{2} w_{2} \leq \alpha .
$$

The constraint states that the average skill level of the distribution chosen by planner cannot exceed $\alpha$.

Allocation. An allocation in this economy is defined as $\mathrm{x}=\left(w_{i}, c_{i}, l_{i}\right)_{i=1,2}$, where $c_{i}$ and $l_{i}$ represent consumption and labor allocation of type $i$.

Feasibility. An allocation is feasible if

$$
\begin{aligned}
& p_{2} c_{2}+p_{1} c_{1} \leq p_{2} w_{2} l_{2}+p_{1} w_{1} l_{1}, \\
& p_{1} w_{1}+p_{2} w_{2} \leq \alpha, \\
& w_{1}, w_{2}, c_{1}, c_{2}, l_{1}, l_{2} \geq 0 .
\end{aligned}
$$

The first inequality here states that total consumption cannot exceed total output. The second inequality makes sure that the average skill level of the distribution chosen by planner does not exceed $\alpha$. Finally, the third inequality is just the non-negativity of skill, consumption and labor allocations.

The timing of the events is as follows. First, the planner chooses the skill distribution. Then, each agent privately draws her skill from this distribution. Finally, the planner chooses the consumption and labor allocations, agents announce their types and receive the corresponding allocation. This informational friction requires the allocation to satisfy the following familiar incentive compatibility conditions:

Incentive compatibility. An allocation is incentive compatible if

$$
\begin{aligned}
& u\left(c_{2}\right)-v\left(l_{2}\right) \geq u\left(c_{1}\right)-v\left(w_{1} l_{1} / w_{2}\right) \\
& u\left(c_{1}\right)-v\left(l_{1}\right) \geq u\left(c_{2}\right)-v\left(w_{2} l_{2} / w_{1}\right)
\end{aligned}
$$

A social planner chooses the level of consumption, labor and the skill distribution to maximize total welfare subject to social feasibility and incentive compatibility constraints.

Social Optimum. An allocation is a social optimum if it solves ${ }^{[5]}$

$$
\operatorname{maxx} p_{2}\left[u\left(c_{2}\right)-v\left(l_{2}\right)\right]+p_{1}\left[u\left(c_{1}\right)-v\left(l_{1}\right)\right]
$$

s.t. (1), (2), (3), (4), and (5).

We denote the optimal allocation by $\left(w_{1}^{*}, w_{2}^{*}, c_{1}^{*}, l_{1}^{*}, c_{2}^{*}, l_{2}^{*}\right)$.

[5] We use a utilitarian social welfare function with equal weights on all agents. However, all of our results hold under any social welfare function that values equality beyond the laissez-faire market outcome. The only feature of this utilitarian social welfare function on which we rely is that the high-skilled type's incentive constraint binds, which is true under any social welfare function that values equality. 
As we are interested in the socially optimal skill distribution, we focus on $w_{1}^{*}$ and $w_{2}^{*}$ in the above problem. First of all, observe that the linear skill constraint given by (2) binds at the socially optimal allocation. We formalize and prove this result with the following lemma.

Lemma 1. In the socially optimal allocation, the skill constraint given by (2) holds with equality.

Proof. Suppose (2) does not hold with equality at the social optimum, say $p_{1} w_{1}+p_{2} w_{2}=\alpha^{\prime}$, where $\alpha-\alpha^{\prime}=\delta>0$. Define a new allocation in which $w_{1}=w_{1}^{*}$ and $w_{2}=w_{2}^{*}+\delta / p_{2}$. Moreover, labor allocations are the same as in the original social optimum, that is, $l_{1}=l_{1}^{*}$ and $l_{2}=l_{2}^{*}$. In this allocation, total output is $\delta l_{2}^{*}$ units higher than total output in the original social optimum. Then, we can always distribute the extra output $\delta l_{2}^{*}$ between agent 1 and 2 such that both incentive constraints, (1) and (2), are still satisfied.

This new allocation provides higher social welfare and satisfies all the constraints of the problem that defines the social optimum. This implies the original social optimum cannot be socially optimal, which is a contradiction.

To understand the question at hand, it is helpful to consider the set of distributions that are available to society. On the one extreme, we can set $w_{1}=0$ and $w_{2}=\alpha / p_{2}$ or $w_{1}=\alpha / p_{1}$ and $w_{2}=0$. In both of these cases, a fraction of agents have very high earnings capacity while the rest are completely unproductive. We call these perfectly unequal skill distributions. On the other extreme, we can set $w_{1}=w_{2}=\alpha$ and make everyone in the society identical. We call this the perfectly equal skill distribution. In between, there is a whole range of skill distributions in which both $w_{1}, w_{2}>0$. In some of these distributions, $w_{1}>w_{2}$ and in some $w_{1}<w_{2}$.

From now on, we denote by $H$ the type that the planner allocates higher skills and by $L$ the other type, i.e., $w_{i}=w_{H}$ and $w_{j}=w_{L}$, if $w_{i}>w_{j}$. In addition, let $p_{i}=p_{H}$ and $p_{j}=p_{L}$. Hence, we redefine an allocation as $\mathrm{x}=\left(w_{H}, w_{L}, c_{H}, l_{H}, c_{L}, l_{L}\right)$. In the next section, we show that when skill constraint is linear, the socially optimal skill distribution involves perfect inequality, meaning $w_{L}=0$ and $w_{H}=\alpha / p_{\mathrm{H}}$.

Rewriting Planner's Problem. Let $\theta=w_{L} / w_{H}$. Observe that $\theta=0$ is the case in which there is perfect inequality in skill distribution. As we increase $\theta$ towards 1 , inequality in skill distribution decreases and at $\theta=1$ there is perfect equality of skills. In the rest of the paper, we will be interested in the value of socially optimal $\theta$. Given definition of $\theta$, we can redefine an allocation by $\mathrm{x}=(\theta, c H, l H, c L, l L)$.

It is a well-known result that only the type $H$ incentive constraint binds under a Utilitarian social welfare function with equal weights. Now we can substitute the skill constraint into the resource constraint and rewrite the problem as:

$$
\max _{x} p_{H}\left[u\left(c_{H}\right)-v\left(l_{H}\right)\right]+p_{L}\left[u\left(c_{L}\right)-v\left(l_{L}\right)\right]
$$


s.t.

$$
\begin{gathered}
p_{H} c_{H}+p_{L} c_{L} \leq \alpha l_{H}+\alpha p_{L} \theta\left(l_{L^{-}} l_{H}\right) /\left(p_{H}+p_{L} \theta\right), \\
u\left(c_{H}\right)-v\left(l_{H}\right) \geq u\left(c_{L}\right)-v\left(\theta l_{L}\right) \\
c_{L}, c_{H}, l_{L}, l_{H} \geq 0 \\
\theta \in[0,1]
\end{gathered}
$$

If the planner sets $\theta=1$, then agents choose their types from the perfectly equal skill distribution where all agents have the skill level $\alpha$. In this case, the right-hand side of feasibility becomes $p_{H} \alpha l_{H}+p_{L} \alpha l_{L}$ and the incentive compatibility constraint disappears.

\section{Socially Optimal Skill Distribution}

Benchmark: Full Information Social Optimum. We first analyze the benchmark case with full information. The planner's problem is the same as above except that there is no incentive compatibility constraint.

It is always optimal for the planner in the full information case to choose the perfectly unequal skill distribution, i.e. giving all of the skill to one of the two types. The intuition is straightforward. In the absence of the incentive constraint, the planner can always equate consumption across agents at zero cost, so the only criterion of optimal skill distribution is productive efficiency. It is easy to see that productive efficiency requires skill distribution to be perfectly unequal. Suppose that this is not true, $\theta^{*} \in(0,1]$. From the first order optimality condition between labor of $H$ and $L$, we have:

$$
v^{\prime}\left(l_{L}^{*}\right)=\theta^{*} v^{\prime}\left(l_{H}^{*}\right)
$$

which implies that $l_{H}^{*} \geq l_{L}^{*}$ since $v^{\prime \prime}>0$ and $\theta^{*} \in(0,1]$. We can find another feasible allocation that strictly improves welfare. Consider a new allocation in which $\hat{\theta}=0, \hat{l}_{L}=0$, and the rest of the allocation stays the same. The feasibility constraint is relaxed because

$$
\alpha l_{H}^{*}+\frac{\alpha p_{L} \hat{\theta}\left(\hat{l}_{L}-l_{H}^{*}\right)}{p_{H}+p_{L} \hat{\theta}}=\alpha l_{H}^{*} \geq \alpha l_{H}^{*}+\frac{\alpha p_{L} \theta^{*}\left(l_{L}^{*}-l_{H}^{*}\right)}{p_{H}+p_{L} \theta^{*}}
$$

and the disutility of L type decreases because

$$
v\left(\hat{l}_{L}\right)=v(0)<v\left(l_{L}^{*}\right)
$$

which indicates that any $\theta \in(0,1]$ cannot be optimal. Therefore, we have the following theorem:

Theorem 1. In the full information social optimum with linear skill constraint, $\theta^{*}=0$.

Private Information Social Optimum. With private information, the choice of skill distribution not only affects productive efficiency, but also, through the incentive constraint, affects the set of consumption distributions available to the planner. In this section, we show that if the skill constraint is linear, then the optimal skill distribution is still perfectly unequal. First consider the effect of skill distribution choice on the production side of the economy. 
From the analysis of the full information case, we know that increasing skill inequality increases total output and decreases total disutility at the same time. Therefore, productive efficiency pushes towards the perfectly unequal skill distribution. However, when skill is private information, increasing skill inequality increases the distortions associated with income redistribution. To see this, consider the incentive constraint of type $H$ which holds with equality at the optimal allocation:

$$
u\left(c_{H}\right)-v\left(l_{H}\right)=u\left(c_{L}\right)-v\left(\theta l_{L}\right)
$$

When the planner increases skill inequality, meaning a decrease in $\theta$, keeping the rest of the allocation intact would violate the incentive constraint. This means that the planner has to accompany the increase in skill inequality by increasing consumption inequality and/or by in- creasing $l_{L}$ relative to $l_{H}$. Both are distortionary and involve a cost to society. Therefore, unlike the full information benchmark, increasing skill inequality not only has a productive efficiency gain but it also has a cost in terms of increasing the distortions associated with income re- distribution. Theorem 2 formally proves that the optimal skill distribution is still perfectly unequal.

Theorem 2. In the private information social optimum, $\theta^{*}=0$.

Proof. We proceed in two steps. Step

1: $\theta^{*}$ cannot be interior.

Suppose not, $\theta^{*} \in(0,1)$, and there are two cases to consider.

Case 1: $l_{H}^{*} \geq l_{L}^{*}$

Consider a new allocation where $\hat{\theta}=0, \hat{l_{H}}=l_{H}^{*}, \hat{l_{L}}=0, \quad \hat{c_{H}}>c_{H}^{*}$ and $\hat{q_{L}}$ such that the incentive constraint still holds,

$$
u\left(\hat{c_{H}}\right)-v\left(l_{H}^{*}\right)=u\left(\hat{c_{L}}\right)-v(0),
$$

and total output is used up for consumption.

To see that we can make the above equality hold in the new allocation, observe the following.

In the new allocation, total output is weakly higher because it is given by

$$
\alpha\left[l_{H}^{*}+p_{L} \theta\left(l_{L^{-}}^{*} l_{H}^{*}\right) /\left(p_{H}+p_{L} \theta\right)\right],
$$

which is decreasing in $\theta$. Now if we gave all of the output to the high type, he would get $\alpha l_{H}^{*} / p_{H}>c_{H}^{*}$.

We can show that $\mathrm{u}\left(\alpha l_{H}^{*} / p_{H}\right)-\mathrm{v}\left(l_{H}^{*}\right)>\mathrm{u}(0)-\mathrm{v}(0)$ because if not, we have

$$
\mathrm{u}(0)-\mathrm{v}(0) \geq \mathrm{u}\left(\alpha l_{H}^{*} / p_{H}\right)-\mathrm{v}\left(l_{H}^{*}\right)>\mathrm{u}\left(c_{H}^{*}\right)-\mathrm{v}\left(l_{H}^{*}\right),
$$

where the second inequality is true because $\alpha l_{H}^{*} / p_{H}>c_{H}^{*}$. Also, observe that $\mathrm{u}(0)-\mathrm{v}(0)>\mathrm{u}\left(c_{H}^{*}\right)-v\left(l_{H}^{*}\right) \geq u\left(c_{L}^{*}\right)-v\left(\theta l_{L}^{*}\right)>u\left(c_{L}^{*}\right)-v\left(l_{L}^{*}\right)$.Therefore, the $c_{H}=c_{L}=l_{H}=l_{L}=0$ allocation gives a strictly higher utility than the efficient allocation, which is clearly incentive compatible and feasible, so efficient allocation cannot be welfare maximizing, which is a contradiction. 
Hence, we have shown that $\mathrm{u}\left(\alpha l_{H}^{*} / p_{H}\right)-\mathrm{v}\left(l_{H}^{*}\right)>\mathrm{u}(0)-\mathrm{v}(0)$. Now, decrease $c_{H}$ and increase $c_{L}$ until this inequality holds with equality, and that is how we construct $\hat{c}_{H}$ and $\hat{c_{L}}$.

Finally, observe that $\hat{c_{H}}>c_{H}^{*}$, because otherwise $\hat{c_{L}}>c_{L}^{*}$, and that would mean

$$
u\left(\hat{c_{H}}\right)-v\left(l_{H}^{*}\right) \leq u\left(c_{H}^{*}\right)-v\left(l_{H}^{*}\right)=u\left(c_{L}^{*}\right)-v\left(\theta l_{L}^{*}\right)<u\left(\hat{q_{L}}\right)-v(0),
$$

which is a contradiction.

$\hat{c_{H}}>c_{H}^{*}$ implies that $H$ type's welfare is strictly higher in the new allocation and the incentive constraint holding with equality implies that so is L type's. Hence, the new allocation strictly improves over the efficient allocation, yielding the desired contradiction.

Case 2: $l_{H}^{*}<l_{L}^{*}$

We can $\operatorname{set} \hat{\theta}=1$, then the resource constraint is relaxed because

$$
\alpha l_{H}^{*}+\frac{\alpha p_{L} \hat{\theta}\left(l_{L}^{*}-l_{H}^{*}\right)}{p_{H}+p_{L} \hat{\theta}}=\alpha l_{H}^{*}+\frac{\alpha p_{L}\left(l_{L}^{*}-l_{H}^{*}\right)}{p_{H}+p_{L}}>\alpha l_{H}^{*}+\frac{\alpha p_{L} \theta^{*}\left(l_{L}^{*}-l_{H}^{*}\right)}{p_{H}+p_{L} \theta^{*}} .
$$

The incentive constraint is also relaxed because

$$
u\left(c_{H}^{*}\right)-v\left(l_{H}^{*}\right)=u\left(c_{L}^{*}\right)-v\left(\theta^{*} l_{L}^{*}\right)>u\left(c_{L}^{*}\right)-v\left(\hat{\theta}_{L}^{*}\right)=u\left(c_{L}^{*}\right)-v\left(l_{L}^{*}\right) .
$$

Thus, it is easy to find another allocation that improves welfare.

Step 2: $\theta^{*}=0$

Suppose not, $\theta^{*}=1$, then it is easy to show $c_{H}^{*}=c_{L}^{*}$ and $l_{H}^{*}=l_{L}^{*}$, but than we can set $\hat{\theta}=0$ and $\hat{l}_{L}=0$. The resource constraint is unaffected because

$$
\alpha l_{H}^{*}+\frac{\alpha p_{L} \theta^{*}\left(l_{L}^{*}-l_{H}^{*}\right)}{p_{H}+p_{L} \theta^{*}}=\alpha l_{H}^{*}+\frac{\alpha p_{L} \hat{\theta}\left(l_{L}^{*}-l_{H}^{*}\right)}{p_{H}+\hat{\theta} p_{L}}>\alpha l_{H}^{*}
$$

We can also set $\hat{c_{H}}>c_{H}^{*}$ and $\hat{\mathcal{L}}$ such that the incentive constraint holds, as we did in Step 1 Case 1:

$$
u\left(\hat{c_{H}}\right)-v\left(l_{H}^{*}\right)=u(\hat{\underline{L}})-v(0)
$$

This improves welfare because $\hat{c_{H}}>c_{H}^{*}$ and $\hat{l}_{L}=0<l_{L}^{*}$.

The analysis in this paper assumes that the social planner can drive the skill level of agents down to zero. In reality, there might be a lower bound on the skill level of agents in the economy. That is, the planner may be facing an additional constraint of the type $w_{1}, w_{2} \geq \kappa$

where $\kappa>0$ refers to a level of skill that the planner cannot transfer from one agent to another. It is important to notice that Theorem 2 may not hold for any positive lower bound $\kappa$. However, following a continuity argument similar to that in Cremer, Pestieau, and Racionero (2010), it is possible to show that for $\kappa$ sufficiently close to zero, our main result holds. That is, as long as this lower bound is sufficiently small compared to the total amount of skills that are available to the planner for distribution, it is socially optimal to distribute the skills in a perfectly unequal way. 


\section{Conclusion}

This paper has studied the socially optimal distribution of skills in a Mirrleesian economy. We have shown that optimal skill distribution is a perfectly unequal one. We acknowledge that our analysis is purely theoretical, and we do not take a stance on any particular interpretation of the skill distribution choice. However, we believe that our model of skill distribution choice could serve as a benchmark for analyzing policy questions regarding education and SBTC. A normative analysis of that kind would require a modification and enrichment of the current model tailored to the specific policy question at hand. We believe that such an analysis of education and SBTC policies based on our model could be an interesting line of future research.

\section{References}

Boadway, R.W. and Pestieau, P. (2006). "Tagging and Redistributive Taxation," Annales d'Economie et de Statistique, (83-84): 123-147.

Bovenberg, A L. and Jacobs, B. (2006). "Redistribtion and Education Subsidies are Siamese Twins," Journal of Public Economics, (85): 2005-2035.

Brett, C. and Weymark, J.A. (2008). "Public Good Provision and the Comparative Statics of Optimal Nonlinear Income Taxation," International Economic Review, 49(1): 255-290.

Cremer, H., Pestieau, P. and Racionero, M. (2010). "Unequal Wages for Equal Utilities,"

International Tax and Public Finance, forthcoming.

Hamilton, J. and Pestieau, P. (2005). "Optimal Income Taxation and the Ability Distribution: Implications for Migration Equilibria," International Tax and Public Finance, 12(1): 29-45.

Hare, P. and Ulph, D. (1979). "On Education and Distribution," The Journal of Political Economy, 87(5): 193-212.

Leung, T. and Yazici, H. (2017). "Optimal Distribution of Skills and Income Taxation under Convex Skill Costs," Working Paper.

Mirrlees, J.A. (1971). “An Exploration in the Theory of Optimal Income Taxation," Review of Economic Studies, 38(114): 175-208.

Naito, H. (1999). "Re-Examination of Uniform Commodity Taxes under a Non-Linear Income Tax System and its Implication for Productive Eficiency," Journal of Public Economics, 71: 165-188.

Simula, L. (2007). "Optimality Conditions and Comparative Static Properties of Non-linear Income Taxes Revisited," Paris School of Economics Working Paper, (2007-15).

Stiglitz, J.E. (1982). "Self-Selection and Pareto Efficient Taxation," Journal of Public Economics, 17: $213-240$.

Violante, G.L. (2009). "Skill-Biased Technical Change," The New Palgrave Dictionary of Economics 